\title{
ON THE NATURE AND DEVELOPMENT OF SOCIAL PRESENCE IN ONLINE COURSE DISCUSSIONS
}

\author{
Karen Swan \\ Research Center for Educational Technology, Kent State University \\ Li Fang Shih \\ School of Business and Technology, Excelsior College
}

\begin{abstract}
"Social presence," the degree to which participants in computer-mediated communication feel affectively connected one to another, has been shown to be an important factor in student satisfaction and success in online courses. This mixed methods study built on previous research to explore in greater depth the nature of social presence and how it develops in online course discussions. The study combined quantitative analyses of survey results from students enrolled in four online graduate courses, and qualitative comparisons of students with the highest and lowest perceptions of social presence. Quantitative results revealed significant correlations between perceived social presence and satisfaction with online discussions, and teased apart the respective influences of the perceived presence of instructors and peers. The findings indicate that the perceived presence of instructors may be a more influential factor in determining student satisfaction than the perceived presence of peers. Correlations with other course and learner characteristics suggest that course design may also significantly affect the development of social presence. Qualitative findings support the quantitative results. In addition, they provide evidence that students perceiving the highest social presence also projected themselves more into online discussions, and reveal meaningful differences in perceptions of the usefulness and purpose of online discussion between students perceiving high and low social presence.
\end{abstract}

\section{KEYWORDS}

Asynchronous Discussion, Social Presence, Online Learning, Interaction, Threaded Discussion, Computer-mediated Communication, Community

\section{INTRODUCTION}

\section{A. Background}

Over the past decade, the Internet has had a profound impact on higher education, enabling the phenomenal growth of online learning. The altered learning environments created by web-based courses not only eliminate barriers of time and space, providing increased access to higher education, they challenge our traditional notions of teaching and learning. A common concern among some educators, for example, is that the mediated nature of online learning might prevent students from developing a sense of belonging with other students, instructors, programs of study and educational institutions [1] which social learning theories $[2,3]$ and immediacy research $[4,5,6,7]$ suggest support learning. In particular, certain communications scholars have argued that differing media have differing capacities to transmit the nonverbal and vocal cues that in face-to-face communications convey social presence and so have questioned the capacity of computer-mediated-communications, in particular, to promote learning $[8,9,10]$. 
Indeed, computer-mediated online discussion has long attracted the attention of researchers precisely because it is significantly different from face-to-face discussion in traditional classrooms. On the one hand, asynchronous online discussion is clearly not as rich in communications cues as traditional classroom discussion. On the other hand, it offers features that may uniquely support learning. In online discussion, for example, all students have a voice and no one, not even an instructor, can dominate the conversation. Accordingly, many researchers note that students perceive online discussion as more equitable and more democratic than traditional classroom discussions [11, 12]. Because it is asynchronous, online discussion also affords participants the opportunity to reflect on their classmates' contributions while creating their own, and to reflect on their own writing before posting it. Perceptions of equitability and greater time for reflection create a certain mindfulness among students and a culture of reflection in an online course $[13,14,15]$.

In addition, and in spite of its "leanness," many researchers familiar with computer-mediated communication have noted what Walther [16] refers to as the "hyperpersonalness" of online discussion. Participants in online discussion, they maintain, seem to project their personalities into online discussion using text alone, creating feelings of social presence that build online discourse communities $[17,18,19]$. An increasing number of studies have examined the perception of interpersonal connections with virtual others as an important factor in the success of online learning [19, 20, 21, 22, 23]. Indeed, Wegerif [24] related individual success or failure in an online course to the extent to which students were able to "cross a threshold from feeling like outsiders to feeling like insiders"

\section{B. Social Presence Research}

"Social presence," initially proposed by Short, Williams, and Christie [8] as "technical social presence," was defined by them as the capacity of the medium itself to present the "salience of the other person in [interpersonal] interaction.” Short and colleagues contended that different communication media convey varying degrees of social presence based on their ability to transmit nonverbal and vocal information. This notion, however, was challenged by researchers in the field who showed that perceived social presence in online interactions varies among participants in the same mediated conversations [16, 20, 25]; and indeed, that many participants perceived online discourse as more personal than traditional classroom discussion. They thus argued that social presence was as much a matter of individual perceptions as an objective quality of the medium.

Gunawardena and Zittle [20], for example, defined social presence as "the degree to which a person is perceived as 'real' in mediated communication" and developed survey items to measure students' perceptions of the social presence of others in a GlobalEd computer conference. Using regression analysis, they found that perceived social presence predicted $60 \%$ of the variance in students' satisfaction with the conference. Their results also indicated that students who felt a higher sense of social presence enhanced their online communication using emoticons to express missing nonverbal cues in textual form.

Danchak, Walther and Swan [26] hypothesized that people communicating online use such textual immediacy indicators to maintain a sense of affective equilibrium in their interactions. Equilibrium is a well-established concept in communications research that describes the ways people interacting face-toface change their behaviors in response to each other in order to maintain an overall balance in the communication process [27]. For example, if one communicator moves closer to another, the other will tend to move away to maintain an equilibrium of distance. Danchak and colleagues argue that participants in environments with less affective communication channels available will evoke more immediacy behaviors to affect a kind of equilibrium of social presence with which they are comfortable. 
Richardson \& Swan [21] used a modified version of Gunawardena and Zittle's [20] survey to study the social presence perceived by students enrolled in seventeen online courses and its relationship to their perceived learning and satisfaction with course instructors. They found all three variables highly correlated. Regression analysis showed that $42 \%$ of the variability in perceived learning was predicted by perceived social presence. Interestingly, this study also found strong correlations between perceived social presence and perceived learning from individual course activities, including learning from activities not typically seen as social, such as individual assignments, tests, and lecture notes. The authors hypothesized that these results might be accounted for by the social presence of instructors and suggested future research should distinguish between the perceived social presence of instructors and that of peers.

Picciano [23] defined social presence as "a student's sense of being and belonging in a course.” He used survey items similar to ones used by Gunawardena and Zittle [20] and Richardson and Swan [21] to measure perceived social presence, interactivity, and learning among students enrolled in an online graduate course in education, and found strong correlations among these variables. However, he found no correlations between these variables and actual performance on tests or written assignments. He further explored these findings by dividing students into groups perceiving low, medium and high social presence. While he found no significant differences between groups on test scores, he did find significant differences on written assignments. Students in the high social presence group scored higher than the medium social presence group who outscored the low social presence group.

Rourke, Anderson, Garrison and Archer [18] regarded social presence as one of the three fundamental "presences" that support learning, the other two being cognitive presence and teaching presence, defining it as "the ability of learners to project themselves socially and affectively into a community of inquiry." Rourke, et al. identified three categories of social presence indicators-affective responses, cohesive responses, and interactive responses - and explored their use in online discussion. Affective responses contain personal expressions of emotion, feelings, beliefs, and values. Cohesive responses are communication behaviors that build and sustain a sense of group commitment, such as greetings and salutations and group or personal reference. Interactive responses are behaviors that provide evidence that others are attending, such as agreement/disagreement, approval and referencing previous messages. Rourke et al. developed protocols for coding online discussion based on these indicators which they established as reliable in a pilot content analysis of two online class discussions.

Swan [19, 28] used Rourke and colleagues' [18] categories and similar indicators of social presence to examine the ways in which social presence developed among students enrolled in an online graduate course in education. She found support for Danchak and colleagues' [26] equilibrium model of students' high use of social presence indicators in their online messaging. In addition, she found changes in the kinds of text-based social presence indicators employed over time. Whereas the use of cohesive indicators decreased as the course progressed, the use of interactive indicators increased. Affective indicators, the most frequently used, remained at about the same level throughout the course.

$\mathrm{Tu}$ [22] also noted the relationship between perceived presence and success in online courses and further linked the development of social presence in online courses to course design. Based on elements of social learning theory, he distinguished three dimensions of course designs which influenced the development of social presence-social context, which includes task orientation, perceptions of privacy, topics, and social processes; online communication, which refers to the language course participants use to communicate and express themselves; and interactivity, which includes reciprocal communication patterns and timely responses. Tu and McIsaac [29] found some support for these dimensions of social presence in a factor analysis of student responses to an online survey concerned with computer-mediated communication tools. They argued that they should be taken into consideration in the design of online courses. 
In summary, research to date has shown that social presence can be strongly felt by participants in computer-mediated communication [16, 29], and that students' perceptions of social presence have a strong influence on their satisfaction with online courses [21, 22, 30], and perhaps their learning from them [18, 23]. Content analyses of online course discussions [18, 19, 28] have identified ways in which participants project their presence using text alone, providing evidence that they make up for the lack of non-verbal and vocal cues through the use of textual social presence indicators [20, 26].

Many questions still remain. For example, most studies of social presence have noted the highly democratic nature of online discussion [11,12] and accordingly conceptualized social presence as a single construct with an emphasis on perceptions of the presence of peers. As noted above, there is some indication that instructor presence may be equally important [21]. While the social presence of instructors has been considered in explorations of "teaching presence" [31, 32], it has not been isolated therein. In addition, while most studies of social presence implicitly locate its development in online discussion, survey questions have not explicitly addressed it in that context. Finally, although researchers have demonstrated both that students perceive the presence of others [17, 20, 21, 23] and that they socially present themselves $[18,19,28]$ in online course discussions, they have not explored links between the two. The study reported in this paper builds on the concepts and methodologies of previous research to address these issues.

\section{Current Study}

The research reported in this paper used survey measures and techniques adapted from those employed by Gunawardena and Zittle [20], Richardson and Swan [21] and Picciano [23] to explore relationships between perceived social presence and satisfaction with online discussions. It differs from these previous studies in that it teased apart the perceived social presence of peers from the perceived social presence of instructors to examine their relative influences on student perceptions, and in that it explicitly addressed these factors in the context of threaded discussion. Because subjects in the study were enrolled in two different courses, sections of which were taught by the same two instructors, the researchers also explored relationships between the development of social presence and instructor and course design variables, as well as demographic and experiential variables. In addition, the study employed the content analysis methodology and social presence indicators developed by Rourke and colleagues [18] and Swan $[19,28]$ to investigate the relationship between perceived social presence and projected presence in online discussions [26]. Specifically, the research adapted techniques employed by Picciano [23] to compare the projected presence of students perceiving the most and the least social presence. Finally, the researchers sought to identify factors contributing to perceptions of social presence in online courses through qualitative analyses of interviews with students perceiving the highest and lowest levels of social presence.

The specific research questions addressed in this study include:

- What is the relationship between students' perceptions of social presence (of peers and of the instructor) and students' satisfaction with online class discussions (perceived interaction, perceived learning and satisfaction with their instructor)?

- How do students with differing levels of perceived social presence project their presence into online class discussions?

- How do students with differing levels of perceived social presence perceive their class discussion?

In the section which follows, the methodology used in the current study is described. That is followed by the reporting of first quantitative results, relating to relationships among variables and differences 
On the Nature and Development of Social Presence in Online Course Discussions

between demographic and experiential groupings, then quantitative results, relating to differences between subjects perceiving the highest and the lowest degrees of social presence in terms of the contents of their discussion postings and their perceptions of online discourse. Finally, the results are reviewed in terms of the research questions and their implications for practice and future research discussed.

\section{METHODOLOGY}

\section{A. Setting}

Subjects for this study were drawn from students participating in four online graduate classes in educational technology offered in the Spring,2003 semester at a large public university in the Northeast. The classes included two sections of Mass Communications and Education and two sections of Educational Computing. Two instructors each taught one section of each course, allowing for comparisons by instructor and course. Both courses required students to participate in weekly threaded discussions; discussion participation, assessed for both quantity and quality, counted for a significant portion of students' final grades. In both courses, discussion threads were prompted by focus questions. In the Mass Communications and Education classes, discussion threads were organized around required readings in six thematic areas. In the Educational Computing classes, discussion threads were organized around issues and practice in four thematic areas. Neither of the two instructors involved were active participants in course discussions, rather they choose to maintain a "restrained presence" [32] by mostly communicating with students through more private channels. One instructor did this through weekly journaling with students, the other used emails to comment on student discussion postings.

\section{B. Subjects}

Fifty-one out of the 91 students enrolled in the classes being studied (56\%) volunteered to fill out an online questionnaire at the end of the semester. This is actually a very good return rate for online surveys, obtained through the support of course instructors. In addition, the demographic characteristics of the volunteer subjects were similar to those of the whole population of students enrolled in the courses studied. Respondents ranged in age from 21 to over 50, with nearly two-thirds falling in the 26 to 45 year old age range. More than two thirds of the respondents were female. While the majority of the survey respondents reported having taken at least one previous online course, $35 \%$ had no previous online experience. Similarly, while nearly two-thirds rated themselves as expert or above average in navigating online discussions on this end of semester survey, a significant number still believed themselves to be novices. The majority of students responding to the survey reported spending one to three hours each week participating in threaded discussions, but more than a third reported spending four to six hours, and several reported spending more than six hours.

\section{Data Sources}

An online questionnaire adapted from Richardson and Swan's [21] survey (Appendix A) was used to gather demographic and experiential information about the respondents and to obtain their rankings of their perceptions of the social presence of their peers and instructors, their satisfaction with their instructors, their perceived learning from online discussions, and their perceptions of interaction among discussion participants on 5-point Likert scales. Respondents were asked to consider their ratings in the specific context of online discussion. The questionnaire also contained three open-ended questions at the end asking respondents about their feelings of community and "knowing" other students in their classes, but answers to these questions are not considered in the analyses reported in this paper. 
In addition, the five respondents with the highest ratings and the five respondents with the lowest ratings of perceived social presence (peers and instructors combined) were identified. All of the discussion postings of these students were captured and coded for social presence indicators using Swan's [19, 28] coding schema (Appendix B). Two coders independently identified social presence indicators in student messages (inter-rater reliability before consensus $=94 \%$ overall), and then met to resolve disagreements through consensus.

Each identified (high or low social presence) student was also interviewed by email and phone concerning their perceptions of and experiences in online discussions. Initial contact with students was made through email approximately three weeks after the end of the semester to enlist their support and establish rapport. In addition, interview questions were emailed to subjects two-days prior to phone interviews to give them time to reflect on their perceptions and recall their experiences. The questions centered on students' message preparation, the ways in which they responded to others, how they formed impressions of their fellow students and instructors, and their feelings about instructors and instructor behaviors (Appendix C). Interviews were conducted by phone and lasted from 45 minutes to one hour. Email was also employed after the interview transcripts were reviewed to clarify and/or confirm particular points.

\section{Data Analyses}

Data from the online survey questionnaires (Appendix A) were collected and responses to the Likert-type questions averaged (where appropriate) by variable to produce quantitative ratings for five variablesperceived social presence of peers (questions 1-8), perceived social presence of instructors (questions 913), satisfaction with instructors (question 14), perceived learning from online discussions (questions 1518), and perceived interaction among discussion participants (question 19). These data were analyzed for relationships among the variables using correlational and regression analyses. Partial correlations were employed to explore the unique influences of peer and instructor presence on the other perception variables. Significant differences in perceived social presence (combined presence of peers and instructors) among differing demographic (age, gender) and other (class, course, instructor, online course experience, discussion participation) variable groups were explored using analyses of variance.

In addition, quantitative content analysis was used to compare the use of social presence indicators in the discussion posting of subjects perceiving the highest and lowest social presence to explore differences in the ways these students projected their own presences in online discussions. Frequencies of social presence indicators found in the messages of the five students perceiving the most and the five students perceiving the least social presence were aggregated for each of the social presence categories (affective, cohesive and interactive indicators). Rourke and colleagues' [18] social presence density index was then applied to calculate each student's use of these per 1000 words of messaging, so that the frequency of their use could be compared between groups experiencing the most and the least social presence.

Finally, transcriptions of interviews with the same selected students were explored and compared across groups using thematic cross-case analysis to explore the ways in which they perceived their online discussion experiences and investigate potential differences between the two groups. The software program ATLAS/ti was used to support the qualitative coding, sorting and reduction of the transcript data. This data was initially organized into cases (the ten students with the highest and lowest ratings of social presence) and coded for the pre-determined categories of interaction, perceptions of instructors, and perceived learning. Themes that emerged between and among categories and cases were identified, compared and interpreted. 


\section{RESULTS}

\section{A. Relationships Among Student Perceptions}

The questionnaire used in this research (Appendix A) was adapted from Richardson and Swan's [21] social presence survey. Changes were made to distinguish between the perceived social presence of peers and instructors, to relate perceived learning specifically to online discussion, and to add a perceived interaction construct. Besides questions eliciting demographic and other potential confounding variables (gender, age, course, previous online courses, proficiency in navigating and time spent in online discussion), respondents were asked to rate their agreement (on a 5-point Likert scale) with statements concerning their perceived social presence of peers (8 statements), their perceived social presence of instructors ( 5 statements), their satisfaction with their instructor ( 1 statement), their perceived learning from online discussion (4 statements), and their perceptions of interaction among course participants (1 statement). Ratings were aggregated and averaged across statements to yield single scores for each variable, and correlations between variables computed to answer the first research question concerning relationships among these variables (Table 1 ).

\begin{tabular}{lllll} 
& SPP & SPI & PL & PI \\
\hline Social pres. of peers (SPP) & & & & \\
Social pres. of inst. (SPI) & $.70^{*}$ & & & \\
Perceived learning (PL) & $.70^{*}$ & $.74^{*}$ & & \\
Perceived interaction (PI) & $.62^{*}$ & $.50^{*}$ & $.55^{*}$ & \\
Satisfaction w/ Inst. (SI) & $.56^{*}$ & $.81^{*}$ & $.74^{*}$ & $.41^{*}$ \\
${ }^{*} \mathrm{p}<.005$ & & & &
\end{tabular}

Table 1: Correlations Between Variables $(n=51)$

As in previous studies [21, 23, 30], all variables were found to be highly correlated, indicating significant relationships among them, with the strongest correlations found between perceptions of social presence (peers and instructors), between these and perceived learning, and between the perceived presence of instructors' and satisfaction with them. Of interest is the extremely strong correlation between the perceived presence of instructors and instructor satisfaction, which indicates that the two are strongly linked for most students, perhaps a single construct for some. The slightly lesser correlations between all variables and perceived interactions should also be noted. These findings may indicate that perceived social presence has a stronger effect on student perceptions than perceived interactivity. Finally, the strong correlations between the perceived presence of peers and instructors, and correlations between each of these and the other perception variables, invites deeper investigation.

The student perception data were accordingly further explored through regression analyses to take a closer look at the composition of the social presence construct and its component parts, peer and instructor presence. Linear regression indicated that the perceived presence variables predicted $49 \%$ of the variance in each other, suggesting their strong interrelationship. Indeed, social presence has commonly been conceived in the literature as a single construct combining the two sorts of perceived presence (peer and teacher). Multiple regressions in the current study revealed that together these two variables were significant joint predictors of satisfaction with instructors (accounting for $50 \%$ of the variance), perceived interaction (accounting for $40 \%$ of the variance), and perceived learning (accounting for $61 \%$ of the variance). However, when their joint contributions were controlled for, differing patterns of predictive relationships were revealed (Table 2). 


$\begin{array}{rccc} & \begin{array}{c}\text { Partial correlations } \\ \text { between each predictor } \\ \text { and perceived learning }\end{array} & \begin{array}{c}\text { Partial correlations } \\ \text { between each predictor } \\ \text { and perceived interaction }\end{array} & \begin{array}{c}\text { Partial correlations } \\ \text { between each predictor } \\ \text { and instructor satisfaction }\end{array} \\ \begin{array}{r}\text { Presence of Peers } \\ \text { Perceived }\end{array} & .36 * * & .44 * & -.03 \\ \begin{array}{r}\text { Presence of Instructors } \\ { }^{\mathrm{p}}<.005 ; * * \mathrm{p}<.05\end{array} & .49^{*} & .10 & .71^{*}\end{array}$

Table 2: Partial Correlations between Social Presence Variables and Perceived Learning, Perceived Interaction, and Instructor Satisfaction $(\mathbf{n}=51)$

For example, the positive correlation between perceived social presence of peers and satisfaction with the instructor (shown in Table 1) became a negative (but non-significant) partial correlation when its relationship with the perceived presence of instructors was partialled out to reveal its unique contribution. The correlation between the perceived presence of instructors and instructor satisfaction, however, remained consistent, indicating that instructor presence was the real determinant of instructor satisfaction. On the other hand, the correlation between the perceived presence of instructors and perceived interaction (shown in Table 1) lost significance when its relationship with the perceived presence of peers was controlled for, while the relationship between the perceived presence of peers and perceived interaction remained significant. This finding indicates that peer presence alone influenced students' perceptions of interactivity in course discussions. Both variables, not only jointly (61\%), but individually predicted perceived learning, although the perceived social presence of instructors accounted for nearly twice (24\%) the variance predicted by the perceived social presence of peers (13\%) when their joint influence was controlled for. This result indicates that the former had a more significant influence on perceived learning than the latter. Taken together, the findings reveal the differing effects of the perceived presence of instructors and peers, providing evidence of separate constructs, and suggest the instructor presence may be more important to student perceptions than the social presence of peers. They clearly deserve further investigation.

\section{B. Factors Influencing Perceptions of Social Presence}

To explore other potential factors influencing perceptions of social presence, the means and standard deviations for students' (combined) perceptions of social presence were compared by classes, courses, instructors, and students' demographic (age and gender groupings) and experiential characteristics (online course experience and time spent on discussion) using analyses of variance. The analyses revealed significant differences in perceived presence only between courses and age groupings.

Students taking the two Mass Communication and Education classes had significantly lower mean social presence scores than students in the two Educational Computing classes $\left(\mathrm{t}_{49}=2.14, \mathrm{p}=.040\right)$, indicating that the students enrolled in the former classes perceived less social presence in online class discussions than the students enrolled in the latter. Differences between courses (but not classes or instructors) points to the importance of instructional design in supporting the development of social presence, and thus supports Tu's [22, 29] contention linking the two. In this case, it may be that the discussions focused on particular readings (in the Mass Communication course) did not elicit as personal responses as discussions asking for participants' opinions on issues or practical experiences. The result clearly deserves further investigation.

Post hoc comparisons of differing perceptions among age groupings showed significant differences between students under 26 and those over 45 . No other differences between age groupings were found. 
This result indicates that younger students were significantly more comfortable with online discussion than older students. While the finding may seem to provide some support for notions of digital natives/digital immigrants [34], interviews with students over 45 suggest that they did not "bond" with other students; indeed, they stated they did not have much in common with their classmates. Differences may thus be more linked to social issues than technology ones. It should also be noted that the result is based on a very small number of responses in each group and may thus be unique to this study. It should nonetheless be further explored.

No significant differences in perceptions of social presence between classes or between students having differing instructors were found, nor were differences based on gender, online course experience, or participation in course discussions. The lack of difference between instructors was probably a reflection of their common competence, and so is probably not meaningful. Indeed, both instructors received very high ratings for instructor satisfaction and perceived social presence. The lack of difference between classes, does, however, underline the importance of the finding of significant differences between courses which suggests design effects. The lack of gender differences may suggest that gender is not an issue online, a finding supported by other studies [35]. Similarly, the lack of differences between more and less experienced online learners suggests that interfaces have evolved to a point where experience using them is no longer an issue, an implication also supported by previous studies [35]. Finally, the lack of differences based on time spent participating in online discussions may provide further evidence that actual interactions are not as important as perceptions of presence and interactivity to student satisfaction. This should be further investigated.

\section{Relationship between Perceived and Projected Presence}

To answer the second research question "How do students with differing levels of perceived social presence project themselves into online course discussions?” combined social presence scores were used to identify the five students perceiving the most and the five students perceiving the least presence of others in class discussions. All the discussion postings of these students were collected and coded for social presence indicators using Swan's [28] classifications of affective, interactive and cohesive indicators (Appendix B), and aggregated by category using Rourke and colleagues' [18] social presence density measure. The social presence density index gives the average frequency of use of the indicators for every 1000 words of text. It is interesting to note in this regard that the messages of students perceiving the least social presence contained on average 1.2 times as many words as those of students perceiving the most social presence. This suggests that perceived presence is not linked to participation in course discussions and gives additional credence to the notion of perceptions trumping actual interactivity.

$\begin{array}{lcccc} & \text { Affective } & \text { Interactive } & \text { Cohesive } & \text { Total } \\ \text { Low SP group } & 17.5 & 6.7 & 4.4 & \mathbf{2 8 . 6} \\ \text { High SP group } & 26.3 & 10.0 & 6.0 & \mathbf{4 2 . 3}\end{array}$

Table 3: Social Presence Densities by Group $(n=10)$

The social presence densities for the messages of the students in the high and low social presence groups are compared in Table 3. It shows that the messages of students perceiving the most presence of others in online discussion also contained far more social presence indicators, on average one and a half times more. Interestingly, although this ratio is consistent across the categories of social presence indicators, most of the difference in each category tended to rest with particular indicators. Among affective indicators, these were valuing and self-disclosure, the most personal of the affective indicators, indicating that students in the high social presence group were more likely to share their feelings and experiences 
with discussion participants. Among cohesive indicators, group reference accounted for most of the difference between high and low social presence groups, indicating that students in the high social presence group were more likely refer to their classmates as a common group, a community of practice [36]. And among interactive indicators, acknowledgement accounted for most of the difference between groups, indicating that students in the high social presence group were more likely to acknowledge and build upon the responses of their peers.

The results, then, suggest that the perception of social presence is related to its presentation. They reveal that the students perceiving the greatest presence of others in online discussions also consistently projected more of their own presence into them, and that they did so in specific ways: by sharing something of themselves with their classmates, by viewing their class as a community, and by acknowledging and building on the responses of their peers. The particular differences in communicative behaviors between students in the high and low social presence groups suggest that they may actually hold quite different perceptions of the nature and purpose of online discussion; indeed, that these differing perceptions shape the ways they both perceive the presence of others and present themselves therein. Such underlying conceptualizations were further explored through interviews with students in the high and low social presence groups.

\section{Differing Perceptions of Online Discussion}

To begin that exploration, the survey data concerning perceived interaction, the perceived social presence of instructors, satisfaction with instructors, and perceived learning were compared between students identified as perceiving particularly high and particularly low social presence. Those comparisons are given in Table 4.

$\begin{array}{lcccc} & \begin{array}{c}\text { Perceived } \\ \text { Interaction }\end{array} & \begin{array}{c}\text { Perc. SP of } \\ \text { Instructors }\end{array} & \begin{array}{c}\text { Instructor } \\ \text { Satisfaction }\end{array} & \begin{array}{c}\text { Perceived } \\ \text { Learning }\end{array} \\ \text { Low SP group } & 3.0 & 3.7 & 4.0 & \mathbf{3 . 2} \\ \text { High SP group } & 5.0 & 4.9 & 5.0 & \mathbf{4 . 8}\end{array}$

Table 4: Mean Perception Rating by Group (n=10)

The results show differences between groups in all perceptions, with the most significant being in what are arguably the more important categories, perceived interaction and perceived learning. The interaction finding is particularly interesting considering students in the low social presence group actually interacted more than their high social presence peers, again pointing to the primacy of perception over actual interactivity. These differences were explored in depth through structured interviews with students in each group. Their answers to the interview questions (Appendix C) were reviewed for emergent themes and compared across groups using cross-case analysis. The qualitative findings support quantitative comparisons between these groups and elaborate on them. They are discussed below in relation to three broad themes - interaction, perceptions of instructors, and perceived learning.

\section{Perceptions of Interaction}

As previously noted, students who perceived high social presence also believed online discussions were more interactive than students perceiving low social presence. Comparative analysis of interview responses also revealed qualitative differences between groups in both how they perceived discussion interactions and how they themselves interacted with their classmates. 
For example, while students who perceived high social presence found the discussion interactions "stimulating," "motivating" and "challenging," students in the low social presence group found them "not challenging," "too agreeable" and "uninteresting." And, while high social presence students appreciated the affective aspects of discussion interactions and found them "supportive," low social presence students definitely did not. One student in this latter group, for example, commented,

"Every once in a while, a couple of students would write some things that were purely social commentary nothing to do with the class. And to tell you the truth, it was a waste of time."

Similarly, although all students appreciated that discussion questions asked them to relate course content to their own experiences and stated they found this helped them better understand concepts, low social presence students were disappointed in the content of their peers' responses, whereas students perceiving high social presence thought they learned as much from reading their classmates responses as they did from crafting their own,

"I think bringing in our own experiences and relating them to the topic/issue gave us better opportunity to gain meaning from the theoretical aspects of the course. I think this method of discussion made the information and the discussions interesting."

High social presence students also found the sharing of personal experiences useful for getting to know their classmates,

"You can learn a lot from people who offer to tell of their personal experiences and often you can get a person that may have had that experience themselves and offer to share their version. Since you are not seeing the people you are interacting with, there has to be a way to make the online experience personable and enjoyable."

Low social presence students, on the other hand, evidenced little interest in getting to know their classmates or found it difficult in the online environment. For example, one stated,

"In class, you know, people come to class so that you could see who is there and who is not, whereas online it was not the case because you couldn't see their faces. I couldn't put any names with any of them, and sometimes, you know, there were two people who had the same names and it was difficult to tell who was who."

Interestingly, although all students reported changing their communication styles to adjust to the asynchronous, text-based format of course discussions, students in the two groups took totally opposite approaches. On the one hand, students in the high social presence group reported adopting a less formal, more personal and expressive tone to make up for the lack of vocal and verbal cues in the asynchronous format,

"I wanted it [the response] to sound like a normal conversation in a regular class. So, I tried to choose my words and my voice and also to add a little humor in the responses."

On the other hand, students in the low social presence group reported adopting a more academic tone in online discussions than they would in a face-to-face situation to "avoid misunderstandings." One student in this group, for example, reported that he usually found himself adopting "a fairly formal tone, rather dry and free of emotion." These findings, as well as those from the content analyses of students' messages, suggest that not all students adapt to the lack of affective cues in the online environment by using more social presence indicators [26]. Indeed, students in this group seemed put off by some of the more personal approaches of their classmates, 
"Some people just wrote stuff down and didn't really think about it. That kind of lowered my impressions of those people. I would know that these people tried to speed through it and didn't feel they were there for learning."

In summary, then, interviews with students revealed that while students in the high social presence group both appreciated and adopted a more conversational and social tone in their online interactions, students in the low social presence group definitely did not. They thus indicate very differing notions of the appropriate nature and purposes of online discussion between these differing groups of students, and, as such, clearly deserve further investigation.

\section{Perceptions of Instructors}

Although all but one student interviewed reported very positive interactions with their instructors, there were meaningful differences between the formers' perceptions and the latter student who felt his instructor was "distant." These differences, as well as more subtle differences between students perceiving high and low social presence are discussed in the following paragraphs.

Most students felt that they had very close relationships with their instructors; indeed, many of the students perceiving low social presence reported that their relationships with their instructors made up for the lack of relationships with their peers. For example, one stated that privately interacting with her instructor reinforced a sense of "intimacy" between her and her instructor. She commented that those "private talks" made her feel as if she had known her instructor for a long time.

In fact, the majority of both high and low social presence students reported that their instructors fostered relationship building through regular interaction, personal sharing, constructive and prompt feedback, and the encouragement of students' knowledge building efforts. For example, one student noted,

"She didn't hold back from saying that she disagreed with anything but she would not lower credit. She would be quick to point out that we all have different opinions and that's okay. This made me see her as a person who would listen to anything and would give feedback without really judging. The time she disagreed with me did not seem to affect our relationship in any way.”

Another stated,

"What was great about my professor was that she took little things she enjoyed about your reply and let you think about what you could improve on and she kept asking leading questions to help you elaborate your thoughts and your mind."

Students perceiving high social presence also commented on the highly personal tone of their instructors' interactions and reported modeling their own interactions after them, noting particularly the ways in which their instructors addressed them by name and shared their personal experiences. Interestingly, the low social presence students did not pick up on these aspects of their language. Similarly, students in the high social presence group noted how instructor behaviors fostered the development of community in their classes, while students in the low social presence group did not.

The one student with negative perceptions of instructor interaction believed that his instructor should have been more in control of the discussions, and more proactive in journaling. He commented, 
"The journal thing is odd. My recollection at this point is that journal thing was not really used. It didn't seem important. I remembered posting a few chatty thoughts at the beginning of the course and that was pretty much of it. . . . I do think it is important to spend time with your instructor but the interaction should be intentional and meaningful. It didn't really do much for me nor for my instructor."

This student seemed to think that responsibility for the journal interaction lay with his instructor and thus appeared to hold a more passive conception of learning; he seemed to believe that he should be taught. He attributed his negative impressions toward his instructor's participation in the discussions mainly to "getting bored" with his classmates' postings and wishing that the instructor would "chime in" more often. He noted, for example,

"She didn't seem to facilitate much, to be honest. By facilitation I mean to participate in the discussions to ask guiding or challenging questions. I didn't see her being there and participating cause she wasn't posting."

In contrast, most students in both groups appreciated their instructors' "restrained presence" [33] in the discussion because they felt it allowed students' to express themselves more freely. For example, one student noted,

"I don't think the professor needs to participate in the discussions a lot. I like the way my instructor participated in the discussions because her input did not influence "mood" or "tone" of the entire discussion. However, when the discussions were not progressing the way they probably ought to she [the instructor] would step in and keep the students on track."

Another remarked,

"Her instruction facilitated the discussions in that she was very clear on what you were supposed to do and on what her expectation of the quality of your responses but not on how were supposed to respond."

The variety of student perceptions noted in their responses to the instructors demonstrates how differently different students respond to similar inputs. This should be born in mind when we try to interpret statistical findings. The extreme difference between the one student who had a negative perception of his instructor should also be noted as it points to certain students who have a more passive conception of learning that needs to be acknowledged. Finally, the more subtle differences in perceptions between students in the high and low social presence groups perhaps suggest an inability on their parts to pick up on social presence indicators in purely text-based communication. All these variations clearly deserve further exploration.

\section{Perceived Learning}

Students who perceived high social presence in the online discussions also believed they learned more from it than did students perceiving low social presence. Comparative analyses of students' interview transcripts revealed meaningful differences in the quality of student perceptions as well. Although all students interviewed stated that they believed they learned something from the discussions, they differed in what and how they thought they learned. Students in the high social presence group attributed their learning to their interactions with their classmates. They reported benefiting directly from the ideas of others. One student, for example, noted, 
"Sometimes in on of those threads, people would share different ways they dealt with classroom management or how they taught specific topics. So I took from them things that I could use in my own profession and they were quite useful (smile)."

Students in the high social presence group also reported benefiting from the multiple perspectives on a variety of issues presented by their classmates. Another student stated,

"When I first read and responded to a discussion question I felt that I had written all that I could on the subject. After reading other people's comments on the same question, I was able to take in different viewpoints and see if it was something that I agreed with or totally disagreed with. Without class discussions I would have never thought twice about the question that I had just answered."

Several students in this group believed that being exposed to multiple perspectives made them "more accepting of different ideas" and helped them "look at things differently." They also noted how the discussion process helped them shape and refine their own perspectives on issues. One student who had no Internet experience before taking a course also remarked on how much she learned about technology.

In contrast, students in the low social presence group attributed their learning from online discussion solely to their own efforts, stating that they learned by articulating their own thinking in writing their messages. Students in this group tended to have low opinions of their classmates' ideas. One student, for example, complained that the messages posted by his peers were "too agreeable" and there were few insightful responses to learn from. He stated,

"Some of the responses I read led me to believe that some of the students in the class were either ignorant about the subject matter, or too stubborn in their way of thinking to take the class content seriously."

Another remarked,

"I learned more from the reading than the discussions. I would say 7/8 of the course was not useful for me personally but I still learned and I like learning and keeping my mind active."

In summary, then, while students in the high social presence group believed they learned a great deal from reading the discussion postings of their classmates, as well as from constructing their own responses, students in the low social presence group attributed their learning solely to their own efforts. These findings perhaps explain some of the differences in perceived learning between groups and so invite further investigation.

Taken as a whole, findings from student interviews reveal significant differences between students in the high and low social presence groups in their conceptions of the nature and purposes of online class discussion. In particular, while students in the high social presence group seemed to embrace the social construction of knowledge and community building [1, 2, 3], students in the low social presence group did not. Indeed, students in the low social presence group seemed either to not be aware of or actively reject the social communications of their peers. They also seemed to overly privilege interactions with their instructors. Such findings clearly have implications for practice. On the one hand, it may be that some students need to be socialized into online communities; that is, they may need to be explicitly introduced to concepts of community building and social construction of knowledge $[1,2,3]$ as well as to ways of projecting their own presence into online discussions [37]. On the other hand, it may be that students are just different and have different needs [38]. It thus may be that different paths for learning 
On the Nature and Development of Social Presence in Online Course Discussions

should be designed into online courses depending on their content and goals, or that different courses offered within programs. Such notions clearly should be further explored.

\section{CONCLUSIONS/DISCUSSION}

\section{A. Major Findings}

This mixed methods study found, as expected, significant relationship between perceived social presence and satisfaction with online discussions. More importantly it teased apart the respective influences of the perceived presence of instructors and peers, and examined the possible effects of other course and learner characteristics on the development of social presence. Qualitative analyses examined the relationship between perceived and projected presence, as well as differences in perceptions of online discussion between students perceiving high and low social presence. Specific findings are summarized below in terms of the research questions.

In terms of relationships among perceptions of social presence and other student perceptions, the findings of the current study support previous findings of strong relationships among these [17, 20, 21, 23, 35]. Specifically, very strong relationships were found between the perceived social presence of peers and that of instructors, and very strong relationships were found between these and perceived learning. Slightly, less strong, but still highly significant, relationships were found between all variables and perceived interaction. These findings may indicate that the social aspects of online discussion are even more important to students than the interactive ones. This suggestion was supported by qualitative content analyses which found that students perceiving the least social presence actually interacted more than students perceiving the most social presence. In addition, an extremely strong relationship between the social presence of instructors and satisfaction with them was found, indicating how important the social aspects of teaching presence [31, 32] may be to students. Interview data support such interpretation, especially among students who do not develop strong social relationships with their peers. The relationships between perceived social presence and perceived interactivity and their effects on perceived learning clearly deserve further investigation, especially as they relate to actual interactions and actual learning [23], perhaps on a micro level.

Additionally, regression analyses were employed to distinguish between the effects of the perceived social presence of peers and that of instructors. These revealed that instructor presence is the sole predictor of instructor satisfaction when interactions between the two presences are controlled for, while peer presence is the sole predictor of perceived interaction. Although both remain significant predictors of perceived learning when interactions between them are removed from the equation, the presence of instructors is much stronger, accounting for nearly twice the variance in perceived learning. These findings demonstrate that the social presence of instructors and the social presence of peers are indeed different constructs that differentially influence other student perceptions. In addition, they suggest that the perceived presence of instructors may be a more significant influence on other student perceptions than perceived peer presence. Interview data again supports such interpretation. These findings clearly deserve further exploration, perhaps along the lines of immediacy research in face-to-face environments $[4,5,6,7]$. In particular, research focusing specifically on the effects of instructor presence on actual learning might resolve some of the ambiguity in research findings to date [23].

Finally, analysis of variance revealed differences in perceived social presence related to differing course designs which suggest that the design of discussion questions and tasks can influence the development of social presence [22, 29]. This finding surely should be further investigated. Learner characteristics, in this study, were not found influential, although a small effect for age was detected. 
In terms of the relationship between perceived and projected presence, content analysis of the discussion postings of the students with the highest and lowest perceptions of social presence established that students perceiving more social presence also used significantly more social presence indicators to project their own presence to their classmates. Specifically, the high social presence students used far more statements of value, self disclosure, and group reference than did students in the low social presence group. Interestingly, interview data revealed that while students in both groups changed their discussion styles to adapt to the asynchronous format, students in the high social presence group reported consciously adopting a more personal and casual style, while students in the low social presence group reported adopting a more formal style. Students in the high social presence group were also were more likely to reference the ideas of their classmates in their own messages. Interview data provides some explanation for these results in that it indicates that students in that group valued their classmates' responses while students in the low social presence group definitely did not. Such findings have important implications for practice and so deserve further exploration.

In terms of differing perceptions of the nature and usefulness of online discussion, comparisons of interview responses between students perceiving the highest and lowest degrees of social presence revealed some noteworthy contrasts. As previously noted, students in the high social presence group valued interaction with their colleagues, especially for the multiple perspectives on issues and the practical advice it afforded, while students in the low social presence group generally found such interaction "a waste of time." Accordingly, while students in both groups believed they learned from participating in the discussion, students in the low social presence group attributed their learning solely to their own efforts in articulating their responses, whereas students in the high social presence group believed they learned at least as much from the responses of their classmates. These results indicate important differences between students participating in online discussion that may be obscured in quantitative analysis and which certainly deserve further investigation.

\section{B. Limitations of the Study}

A major limitation of the research reported in this paper is that it explored social presence in the context of graduate courses in educational technology taught by two highly competent instructors who were well aware of social presence issues and consciously worked to develop relationship with and among their students. It thus clearly is not representative of all online courses, instructors or students, and as such certain of its findings may not be generalizable to other contexts. In particular, results relating to instructor and/or student characteristics are obviously limited. However, the limited context makes significant findings regarding course design factors more meaningful. Similarly, findings indicating differing effects of the perceived presence of instructors and peers are meaningful, although the particular differences found may be specific to the context of the research. Future research thus should investigate these issues with differing instructors, student populations, and subject areas.

Another limitation of the current study is its reliance on self-reports in both the student surveys and student interviews. Of course, this reflects the purposes of the study-to explore the nature and development of social presence, which is a perceptual construct. However, the effects of such perceptions on actual learning were not explored. Such effects should be a focus of future research, as should relationships between specific instructor and student behaviors and actual learning.

\section{Implications for Practice}

The results of the research reported in this paper have important implications for practice. Research on online communities has stressed the importance of promoting socio-emotional bonding among learners to 
sustain knowledge co-construction among learners [1, 3, 4, 7]. The findings of the current study support such claim and provide some direction for enhancing the development of social presence among students participating in online discussion.

Firstly, they highlight the importance of the design of course discussions. In particular, they suggest that discussion topics and grading rubrics which encourage the sharing of personal experience are especially supportive of the development of social presence. They thus indicate that course designers and instructors should seek ways to evoke personal experience in discussion starters and other design factors. Future research that compares specific discussion designs might prove fruitful.

Secondly, the results demonstrate the importance of instructor presence and instructor behaviors in the development of social presence among discussion participants. They thus suggest that instructors should be made aware of the importance of such development and ways to support it, perhaps through professional development. Shea and colleagues' [32] work provides some ideas for doing so. Future research might explore these and other efforts directed at improving instructor presence.

Finally, the results of the current study demonstrate meaningful differences in student perceptions of the nature and purposes of online discussion, similar to those noted by Ehlers [38]. They thus indicate that student orientations should include some introduction to both the importance of social presence and social learning and ways of perceiving and projecting it in online course discussions. Garrison, Cleveland-Innes and Fung's [39] notion of student role adjustment might prove very useful in this respect. It clearly deserves further investigation. On the other hand, it may be that online students have very different learning styles irrespective of orientations [38]. Thus it may be profitable to explore providing different kinds of learning experiences for differing student needs. Polhemus, Danchak, Assis and Swan's [40] work on adaptive hypermedia might provide guidance in this respect. It too clearly deserves further study.

\section{Educational Significance}

The results of this study not only extend our understanding of both the importance and the nature of the development of social presence in online course discussions, but suggest ways to support such development. Specifically, results highlight the importance of instructor presence, instructional design, and students' own presentation of themselves in online discussion. They suggest that social presence can be fostered through pro-social instructor behaviors and careful design of online discussions, as well as faculty development focusing on social presence issues. In addition, they suggest that explicit training for students in the importance of social presence, ways of presenting themselves online and the nature of online discussion might help particular students better adapt to the medium. It also may be that alternative paths for different kinds of students should be designed into courses and/or programs. This and previous studies have demonstrated links between perceived social presence and learning; such findings have both theoretical and practical significance.

\section{REFERENCES}

1. Haythornthwaite, C. Building social networks via computer networks: Creating and sustaining distributed learning communities. In K. Renninger, \& W. Shumar (eds.) Building Virtual Communities: Learning and Change in Cyberspace. Cambridge: Cambridge University Press, 2002.

2. Vygotsky, L. S. Mind in Society. Cambridge, MA: Harvard University Press, 1978.

3. Lave, J. and E. Wenger, E. Situated Learning: Legitimate Peripheral Participation. Cambridge: Cambridge University Press, 1991. 
4. Richmond, V. P., J. S. Gorham, and J. McCrosky. The relationship between selected immediacy behaviors and cognitive learning. In M. McLaughlin (ed.) Communication Yearbook 10, 574-590. Beverly Hills, CA: Sage, 1987.

5. Weiner, M. \& A. Mehrabian. Language Within Language: Immediacy, a Channel in Verbal Communication. New York: Appleton-Century-Crofts, 1968.

6. Christophel, D. The relationship among teacher immediacy behaviors, student motivation, and learning. Communication Education 39(4): 323-240, 1990.

7. Rodriguez, J. L., T. G. Plax, and P. Kearney. Clarifying the relationship between teacher nonverbal immediacy and student cognitive learning: affective learning as the central causal mediator. Communication Education 45: 293-305, 1996.

8. Short, J., E. Williams, E and B. Christie. The Social Psychology of Telecommunications, 65. Toronto: Wiley, 1976.

9. Rice, R. E. Contexts of research in organizational computer-mediated communication. In M. Lea (ed.), Contexts of Computer-Mediated Communication. New York: Harvester Wheatsheaf, 1992.

10. Picard, R. W. Affective Computing. Cambridge, MA: MIT Press, 1997.

11. Harasim, L. On-line Education: Perspectives on a New Environment. New York: Praeger, 1990.

12. Levin, J. A., H. Kim, and M. M. Riel. Analyzing instructional interactions on electronic message networks. In L. Harasim (ed.), On-line Education: Perspectives on a New Environment New York: Praeger, 1990.

13. Hiltz, S. R. The Virtual Classroom: Learning without Limits via Computer Networks. Norwood, NJ: Ablex. 1994.

14. Poole, D. M. Student participation in a discussion-oriented online course: a case study. Journal of Research on Computing in Education 33(2): 162-177, 2000.

15. Garrison, D. R. Cognitive presence for effective asynchronous online learning: the role of reflective inquiry, self-direction and metacognition. In J. Bourne \& J. C. Moore (eds.), Elements of Quality Online Education: Practice and Direction, 47-58. Needham, MA: Sloan-C, 2003.

16. Walther, J. Interpersonal effects in computer mediated interaction. Communication Research 21(4): 460-487, 1994.

17. Gunawardena, C. Social presence theory and implications for interaction and collaborative learning in computer conferences. International Journal of Educational Telecommunications 1(2/3): 147-166, 1995.

18. Rourke, L., T. Anderson, D. R. Garrison, and W. Archer. Assessing social presence in asynchronous text-based computer conferencing. Journal of Distance Education 14(2): 50, 2001.

19. Swan, K. Building communities in online courses: the importance of interaction. Education, Communication and Information 2(1): 23-49, 2002.

20. Gunawardena, C. and F. Zittle. Social presence as a predictor of satisfaction within a computer mediated conferencing environment. American Journal of Distance Education 11(3): 8-26, 1997.

21. Richardson, J. C. and K. Swan. Examining social presence in online courses in relation to students' perceived learning and satisfaction. Journal of Asynchronous Learning Networks 7(1): 6888, 2003.

22. Tu, C. H. On-line learning migration: From social learning theory to social presence theory in CMC environment. Journal of Network and Computer Applications 23(1): 27-37, 2000.

23. Picciano, A. G. Beyond student perceptions: Issues of interaction, presence and performance in an online course. Journal of Asynchronous Learning Networks 6(1): 24, 2002.

24. Wegerif, R. The social dimension of asynchronous learning networks. Journal of Asynchronous Learning Networks 2(1): 34-49, 1998.

25. Byam, N. The emergence of community in computer-mediated communication. In S. G. Jones (ed.) Cybersociety. Newbury Park, CA: Sage, 1995.

26. Danchak, M. M., J. B. Walther, and K. Swan. Presence in mediated instruction: bandwidth, behavior, and expectancy violations. Orlando, FL: Paper presented at the Seventh Annual Sloan-C International Conference on Online Learning, 2001. 
On the Nature and Development of Social Presence in Online Course Discussions

27. Argyle, M. and M. Cook. Gaze and Mutual Gaze. Cambridge: Cambridge University Press, 1976.

28. Swan, K. Developing social presence in online discussions. In S. Naidu (ed), Learning and Teaching with Technology: Principles and Practices, 147-164. London: Kogan Page, 2003.

29. Tu, C-H. and M. McIsaac. The relationship of social presence and interaction in online classes. The American Journal of Distance Education 16(3): 131-150, 2002.

30. Gunawardena, C., C. A. Lowe, and T. Anderson. Analysis of a global online debate and the development of an interaction analysis model for examining social construction of knowledge in computer conference. Journal of Educational Computing Research 17(4): 397-431, 1997.

31. Anderson, T., L. Rourke, D. R. Garrison, and W. Archer. Assessing teaching presence in a computer conferencing context. Journal of Asynchronous Learning Networks 5(2): 2001.

32. Shea, P. J., A. M. Pickett and W. E. Pelz. A follow-up investigation of "teaching presence" in the SUNY Learning Network. Journal of Asynchronous Learning Networks 7(2): 61-80, 2003.

33. Vandergrift, K. E. The anatomy of a distance education course: a case study analysis. Journal of Asynchronous Learning Networks 6(1): 76-90, 2002.

34. Prensky, M. Digital natives, digital immigrants. On the Horizon, NCB University Press 9(1): 2001.

35. Swan, K., P. Shea, E. Fredericksen, A. Pickett, W. Pelz, and G. Maher. Building knowledge building communities: consistency, contact and communication in the virtual classroom. Journal of Educational Computing Research 23(4): 389-413, 2000.

36. Wenger, E. Communities of Practice: Learning, Meaning, and Identity. New York: Cambridge University Press, 1997.

37. Pelz, B. (My) Three principles of effective online pedagogy. Journal of Asynchronous Learning Networks 8(3): 33-46, 2004.

38. Ehlers, U-D. Quality in e-learning from a learner's perspective. European Journal of Open and Distance Learning, 2004-I, 2004. Online: http://www.eurodl.org/materials/contrib/2004/Online Master_COPs.html

39. Garrison, D. R., M. Cleveland-Innes, and T. Fung. Student role adjustment in online communities of inquiry: model and instrument validation. Journal of Asynchronous Learning Networks 8(2): 61-74, 2004.

40. Polhemus, L., M. Danchak, A. Assis, and K. Swan. A cyclic approach to online course design. Paper presented at the Tenth Annual Sloan-C International Conference on Asynchronous Learning Networks, Orlando, FL, November, 2004.

\section{ABOUT THE AUTHORS}

Karen Swan is Research Professor in the Research Center for Educational Technology at Kent State University. Dr. Swan's research has been focused mainly in the general area of media and learning on which she has published and presented nationally and internationally. Her current research focuses on online learning, and on student learning in ubiquitous computing environments. Dr. Swan has also authored several hypermedia programs, co-edited a book on Social Learning from Broadcast Television and is currently working on a co-edited book on ubiquitous computing. She served as a project director on several large scale grants including work for the US Department of Education, the National Science Foundation, and the NYC Board of Education. She is an Effective Practices Editor for the Sloan Consortium, the Special Issues Editor for the Journal of Educational Computing Research, and Editor of the Journal of the Research Center for Educational Technology.

Li fang Shih is the Director of Online Course Management of School of Business and Technology at Excelsior College. She received a doctorate in Curriculum and Instruction with specialization in Instructional Technology at State University at Albany in August, 2004. She have worked on research in the online learning environment and presented in the national conferences since 1999. Her current interests are in webbased course development with further interests in the instructional theories that facilitate online learning. 


\section{APPENDIX A: SOCIAL PRESENCE SURVEY}

\section{Part I}

Name:

Class:

Gender (M/F):

Age (25 or under; 26-35; 36-45; over 45): $\quad$ Number of previous online courses taken:

How proficient are you in navigating threaded discussions (expert, above average, average, below average, novice)?

How many hours a week do you spend on online discussions for this course?

Part II: Please indicate the degree to which you Agree/Disagree with each statement as it relates to your online class discussion $(1=$ =strongly disagree, $2=$ =disagree, $3=$ =uncertain, $4=$ =agree, $5=$ =strongly agree):

1. Online or web-based education is an excellent medium for social interaction.

$$
\begin{array}{lllll}
1 & 2 & 3 & 4 & 5
\end{array}
$$

2. I felt comfortable conversing through this medium.

$$
\begin{array}{lllll}
1 & 2 & 3 & 4 & 5
\end{array}
$$

3. The "Meet Your Classmates" section enabled me to form a sense of online community.

$$
\begin{array}{lllll}
1 & 2 & 3 & 4 & 5
\end{array}
$$

4. I felt comfortable participating in course discussions.

$$
\begin{array}{lllll}
1 & 2 & 3 & 4 & 5
\end{array}
$$

5. I felt comfortable interacting with other participants in the course.

$$
\begin{array}{llll}
1 & 2 & 3 & 4
\end{array}
$$

6. I felt that other participants in the course acknowledged my point of view.

$$
\begin{array}{lllll}
1 & 2 & 3 & 4 & 5
\end{array}
$$

7. I was able to form distinct individual impressions of some course participants.

$\begin{array}{lllll}1 & 2 & 3 & 4 & 5\end{array}$

8. Online discussions enabled me to form a sense of community.

9. The instructor created a feeling of online community.

$\begin{array}{lllll}1 & 2 & 3 & 4 & 5\end{array}$

$\begin{array}{lllll}1 & 2 & 3 & 4 & 5\end{array}$

10. The instructor facilitated discussions in the course.

$\begin{array}{lllll}1 & 2 & 3 & 4 & 5\end{array}$

11. I was able to form distinct individual impressions of the instructor in this course.

$$
\begin{array}{lllll}
1 & 2 & 3 & 4 & 5
\end{array}
$$

12. I felt comfortable conversing with the instructor through this medium.

13. My point of view was acknowledged by the instructor.

$\begin{array}{lllll}1 & 2 & 3 & 4 & 5\end{array}$

$\begin{array}{lllll}1 & 2 & 3 & 4 & 5\end{array}$

14. The instructor for this course met my expectations
1
2
34
5

15. I was able to learn from the online discussions.
1
2
34
5

16. I was stimulated to do additional reading or research on topics discussed in the online discussions.
12
3
4
5

17. Participating in the online discussions was a useful experience.
1
2
3
4
5

18. Participating in the online discussions enabled me to form multiple perspectives.
1
2
3
4
5

19. I thought there was a great deal of interaction in the online discussions.
1
2
3
4
5 


\section{Part III}

20. Do you feel that you actually "know" some of your classmates, even though you only communicated with them through online? Why or why not?

21. How would you define an online community? Was a community formed in this online class? Please provide some examples of how the community formed?

22. Please specify a list of characteristics that you could/did perceive about this online community?

\section{APPENDIX B: SOCIAL PRESENCE INDICATORS}

Affective Indicators:

\begin{tabular}{|c|c|c|c|}
\hline Indicator & Defined & Examples & Supporting Sources \\
\hline Paralanguage (PL) & $\begin{array}{l}\text { features of text used to } \\
\text { convey emotion (i.e. } \\
\text { emoticons, exaggerated } \\
\text { punctuation or spelling) }\end{array}$ & $\begin{array}{l}\text { Someday . . . . . .; How } \\
\text { awful for you :-(; } \\
\text { MathCAD is definitely } \\
\text { NOT stand alone!!!!!!! }\end{array}$ & $\begin{array}{l}\text { Bussman, 1998; Poole, } \\
2000 \text {; Rourke et al., } \\
2001\end{array}$ \\
\hline Emotion (EM) & $\begin{array}{l}\text { use of descriptive words } \\
\text { that indicate feelings (i.e. } \\
\text { love, sad, hate, silly) }\end{array}$ & $\begin{array}{l}\text { When I make a spelling } \\
\text { mistake, I look and feel } \\
\text { stupid }\end{array}$ & emergent \\
\hline Value (VL) & $\begin{array}{l}\text { expressing personal } \\
\text { values, beliefs \& attitudes }\end{array}$ & $\begin{array}{l}\text { I think it is a necessary } \\
\text { evil; I feel our children } \\
\text { have the same rights }\end{array}$ & emergent \\
\hline Humor (H) & $\begin{array}{l}\text { use of humor-teasing } \\
\text { cajoling, irony, sarcasm, } \\
\text { understatement, }\end{array}$ & $\begin{array}{l}\text { God forbid leaving your } \\
\text { house to go to the library }\end{array}$ & $\begin{array}{l}\text { Eggins \& Slade, 1997; } \\
\text { Poole, } 2000\end{array}$ \\
\hline Self-disclosure (SD) & $\begin{array}{l}\text { sharing personal } \\
\text { information, expressing } \\
\text { vulnerability }\end{array}$ & $\begin{array}{l}\text { I sound like an old lady; I } \\
\text { am a closet writer; We } \\
\text { had a similar problem }\end{array}$ & $\begin{array}{l}\text { Cutler, 1995; Poole, } \\
\text { 2000; Rourke et al., } \\
2001\end{array}$ \\
\hline
\end{tabular}

\section{Cohesive Indicators:}

\begin{tabular}{|r|l|l|l|}
\hline \multicolumn{1}{|c|}{ Indicator } & \multicolumn{1}{|c|}{ Defined } & \multicolumn{1}{c|}{ Examples } & \multicolumn{1}{c|}{ Supporting Sources } \\
\hline Greetings \& Salutations & greetings, closures & $\begin{array}{l}\text { Hi Mary; That's it for } \\
\text { now, Tom }\end{array}$ & $\begin{array}{l}\text { Poole, 2000; Rourke et } \\
\text { al., 2001 }\end{array}$ \\
\hline Vocatives (V) & $\begin{array}{l}\text { addressing classmates by } \\
\text { name }\end{array}$ & $\begin{array}{l}\text { You know, Tamara, ...; I } \\
\text { totally agree with you } \\
\text { Katherine }\end{array}$ & $\begin{array}{l}\text { Christenson \& Menzel, } \\
\text { 1998; Gorham, 1998 }\end{array}$ \\
\hline Group Reference (GR) & $\begin{array}{l}\text { referring to the group as } \\
\text { "we," "us,” "our” }\end{array}$ & $\begin{array}{l}\text { We need to be educated; } \\
\text { Our use of the Internet } \\
\text { may not be free }\end{array}$ & Rourke et al., 2001 \\
\hline Social Sharing (SS) & $\begin{array}{l}\text { sharing information } \\
\text { unrelated to the course }\end{array}$ & $\begin{array}{l}\text { Happy Birthday!! to both } \\
\text { of you!!! }\end{array}$ & Rourke et al., 2001 \\
\hline Course Reflection (RF) & $\begin{array}{l}\text { reflection on the course } \\
\text { itself }\end{array}$ & $\begin{array}{l}\text { A good example was the } \\
\text { CD-ROM we read about }\end{array}$ & emergent \\
\hline
\end{tabular}

Interactive Indicators:

\begin{tabular}{|r|l|l|l|}
\hline Indicator & \multicolumn{1}{|c|}{ Defined } & \multicolumn{1}{c|}{ Examples } & Supporting Sources \\
\hline Acknowledgement (AK) & $\begin{array}{l}\text { referring directly to the } \\
\text { contents of others' } \\
\text { messages; quoting from } \\
\text { others' messages }\end{array}$ & $\begin{array}{l}\text { Those old machines sure } \\
\text { were something; I agree } \\
\text { that it is the quickest way }\end{array}$ & Rourke et al., 2001 \\
\hline $\begin{array}{r}\text { Agreement/ } \\
\text { Disagreement (AG) }\end{array}$ & $\begin{array}{l}\text { expressing agreement or } \\
\text { disagreement with others' } \\
\text { messages }\end{array}$ & $\begin{array}{l}\text { I'm with you on that; I } \\
\text { agree; I think what you } \\
\text { are saying is so right }\end{array}$ & $\begin{array}{l}\text { Poole, 2000; Rourke et } \\
\text { al., 2001 }\end{array}$ \\
\hline
\end{tabular}




\begin{tabular}{|c|l|l|l|}
\hline Approval (AP) & $\begin{array}{l}\text { expressing approval, } \\
\text { offering praise, } \\
\text { encouragement }\end{array}$ & $\begin{array}{l}\text { You make a good point; } \\
\text { Right on; Good luck as } \\
\text { you continue to learn }\end{array}$ & emergent \\
\hline Invitation (I) & $\begin{array}{l}\text { asking questions or } \\
\text { otherwise inviting } \\
\text { response }\end{array}$ & $\begin{array}{l}\text { Any suggestions? Would } \\
\text { you describe that for me }\end{array}$ & Rourke et al., 2001 \\
\hline Personal Advice (PA) & $\begin{array}{l}\text { offering specific advice to } \\
\text { classmates }\end{array}$ & $\begin{array}{l}\text { The CEC website might } \\
\text { have some references }\end{array}$ & emergent \\
\hline
\end{tabular}

\section{APPENDIX C: INTERVIEW QUESTIONS}

1. What did you think about when you were preparing to post a message to the course discussion? Did you think about how you would sound to others? Did you think about how what you say would influence how others think of you?

2. Did you use any strategies to put "personal” touches in your messages? If so, why did you want to make yourself sound more personal in online discussions?

3. How did the ways other students wrote their messages influence your impressions of them? Did others' language use influence that of yours? If so, how?

4. What did you think about when you were responding to others' message?

5. Did you choose certain people to respond to? Have you built a sense of bonding with those students?

6. Do you think a sense of bonding is important to learning in asynchronous learning environments? Why or why not?

7. What were the criteria you used while choosing which messages to respond to?

8. What are your impressions of your instructor? How were these impressions formed?

9. From my observation of the online class discussions, I noticed that your instructor encouraged you to refer to your personal experiences while answering most of the questions? What do you think about this? Do you think this made the discussions more personal?

10. Did your instructor's style of writing influence the way you constructed your messages in the class? If so, how?

11. Did you notice that your instructor did not often participate in the class discussions? What do you think about this? Do you think they none-the-less facilitated the class discussions? If so, how?

12. Would you prefer your instructor to participate in discussions publicly instead of giving private personal feedback to your postings? Why or why not?

13. Do you think it is important that you have regular and personal interaction with your instructor? Why or why not?

14. As the tone of your voice is not available in the online environment, did you find it as a big constraint when communicating with your peers? If so, what did you do to overcome the constraints? 